\title{
Profile of antiretroviral agents use in Colombia
}

\author{
Jorge E. Machado-Alba, Miguel A. Atehortúa-Otero, Diego A. Cortés-Mejía \\ Grupo de Investigación en Farmacoepidemiología y Farmacovigilancia, \\ Universidad Tecnológica de Pereira, Audifarma, S. A., Pereira, Colombia
}

\begin{abstract}
Introduction: Since the beginning of the epidemic, human immunodeficiency virus (HIV) has taken more than 36 million lives.

Objective: To determine the antiretroviral drug prescription patterns in a population of individuals with HIV infection in Colombia.

Materials and methods: Cross-sectional study analyzing the profiles of patients treated with antiretroviral drugs between April $1^{\text {st }}$ and September $30^{\text {th }}, 2015$. The sociodemographic, pharmacological, and comorbidity variables were identified. Individuals with a positive diagnosis of HIV of all ages and both genders were included.

Results: We found 641 patients with a mean age of $39.0 \pm 17$ years who were predominantly male $(60.2 \%)$. The most used medications were lamivudine-zidovudine (51.6\%), lopinavir-ritonavir (36\%) and efavirenz $(24.5 \%)$. The combination of lamivudine-zidovudine plus lopinavir-ritonavir was the most prescribed regimen (29.5\%), but a total of 80 different regimens was identified. Being an adult between the ages of $45-64$ years $(\mathrm{OR}=2.25 ; 95 \% \mathrm{Cl} 1.367-3.713)$ was associated with a greater probability of receiving 4 or more antiretrovirals. A total of $267(41.6 \%)$ patients used at least one comedication (range: $1-18$ drugs), especially anti-ulcer (57.3\%), lipid-lowering (28.8\%) and anti-hypertensive (28.5\%) drugs.

Conclusions: Patients undergoing antiretroviral treatment are receiving medications with elevated intrinsic values at the recommended doses and present comorbidities associated with chronic agerelated conditions. However, these patients receive a great variety of regimens that are not included in the clinical practice guidelines.
\end{abstract}

Key words: Acquired immunodeficiency syndrome; antiretroviral therapy, highly active; drug prescriptions; pharmacoepidemiology.

doi: https://doi.org/10.7705/biomedica.v38i4.3885

\section{Perfil de utilización de antirretrovirales en Colombia}

Introducción. La infección por HIV es una pandemia que actualmente se controla con el tratamiento farmacológico, el cual, además, prolonga la expectativa de vida del paciente.

Objetivo. Determinar los patrones de prescripción de fármacos antirretrovirales en una población de personas afiliadas al régimen contributivo del Sistema General de Seguridad Social en Salud de Colombia, durante el 2015.

Materiales y métodos. Se hizo un estudio de corte transversal para analizar la formulación de fármacos antirretrovirales en pacientes tratados con estos entre el $1^{\circ}$ de abril y el 30 septiembre del 2015. Se determinaron las variables sociodemográficas, farmacológicas y las comorbilidades, y el análisis estadístico se hizo mediante SPSS ${ }^{\mathrm{TM}}$, versión 23.0.

Resultados. Se hallaron 641 pacientes, la mayoría $(60,2 \%)$ hombres, con una edad media de $39,0 \pm 17$ años. Los medicamentos más empleados fueron lamivudina-zidovudina (51,6 \%), lopinavirritonavir (36 \%) y efavirenz $(24,5 \%)$. La asociación lamivudina-zidovudina más lopinavir-ritonavir fue el esquema más prescrito (29,5\%), pero se encontraron 80 esquemas diferentes. El ser un adulto entre 45 y 64 años (odds ratio=2,25; $I_{95 \%} 1,367-3,713 ; p=0,001$ ) se asoció con una mayor probabilidad de recibir cuatro o más antirretrovirales. Del total de pacientes, 267 (41,6 \%) recibían más de un medicamento simultáneamente (rango: 1-18 fármacos), especialmente fármacos contra las úlceras $(57,3 \%)$, hipolipemiantes $(28,8 \%)$ y antihipertensivos $(28,5 \%)$.

\section{Author's contributions:}

Jorge E. Machado-Alba and Miguel A. Atehortúa-Otero: data collection and data analysis

All authors participated in the description of results, the discussion of the article and the drafting of the manuscript. 
Conclusiones. Los pacientes en tratamiento antirretroviral están recibiendo medicamentos de elevado valor intrínseco en las dosis recomendadas, y presentan las mismas comorbilidades asociadas con las condiciones crónicas relacionadas con la edad. Además, reciben una gran variedad de esquemas que no se encuentran incluidos en las guías de práctica clínica.

Palabras clave: síndrome de inmunodeficiencia adquirida; terapia antirretroviral altamente activa; prescripciones de medicamentos; farmacoepidemiología.

doi: https://doi.org/10.7705/biomedica.v38i4.3885

Since the beginning of the epidemic, human immunodeficiency virus (HIV) has taken more than 36 million lives $(1,2)$. Towards the end of 2012, approximately 35.3 million people were estimated to be living with HIV (3). This increase in prevalence has largely been a consequence of the transition of HIV from a highly lethal disease to a chronic and treatable condition (4). This transition has mostly been the product of the use and expansion of antiretroviral therapy (ART) worldwide. Between 1995 and 2010, ART use avoided an estimated 5.2 million deaths related to acquired immunodeficiency syndrome (AIDS) in middle- and low-income countries; moreover, ART resulted in a $28 \%$ reduction in deaths between 2006 and $2012(3,5)$.

ART has been transformed, and multiple drugs have been added to the therapeutic arsenal (6). Towards the end of the 1990s, the course of the HIV epidemic changed drastically due to the approval of three protease inhibitors (PIs) for HIV and the use of highly active antiretroviral treatment (HAART). The combined therapy led to a rapid reduction in viral RNA, improvement of immune functions, regression of hard-to-treat opportunistic infections and a reduction in mortality (7).

In 2014, 28 antiretroviral drugs belonging to six different classes of action mechanisms were approved for use in the United States (7). Currently, the recommended ART regimens are less toxic, more effective, have a lower pill burden and are dosed with a lower frequency than the original regimens based on nucleoside reverse transcriptase inhibitors (NRTIs) (8). A standard treatment combines two NRTIs with a non-nucleoside reverse transcriptase inhibitor (NNRTI), a PI or an integrase inhibitor (9). In lowand medium-income countries, the World Health

\footnotetext{
Corresponding author:

Jorge Enrique Machado-Alba, Grupo de Investigación en Farmacoepidemiología y Farmacovigilancia, Universidad Tecnológica de Pereira-Audifarma, S. A., Calle 105 № 14-140, Pereira, Colombia

Telephone: (576) (310) 832 6970; fax: (576) 3137822

machado@utp.edu.co
}

Organization (WHO) recommends the use of ART with standardized first and second line regimens of two NRTIs plus one PI enhanced with ritonavir. In these countries, monitoring the viral load is a cost-effective tool for evaluating treatment, but resistance tests are not always available (10).

Colombia has a health system that provides universal coverage through a paid regime and a second system subsidized by the state. Access to ART for patients diagnosed with HIV/AIDS is covered by the benefits plan contained in a manual of medications called the Obligatory Health Plan (Plan Obligatorio de Salud, POS), which is updated and includes the majority of the drugs of the group (11). However, the low accessibility to resistance tests for HIV and scarce adherence to clinical practice guidelines have given rise to the implementation of diverse treatment protocols for HIV/AIDS. Some of these protocols are adopted empirically and are not based on recommendations from scientific evidence (12). This study describes the antiretroviral use patterns in the Colombian population and identifies the main associated variables with the aim of improving knowledge on the pharmacological management of this disease and promoting the rational use of medications in the context of public health.

\section{Materials and methods}

A cross-sectional study was conducted to investigate the use of antiretroviral drugs in a sample of individuals affiliated with the contributive or paid scheme of the Health System of Colombia in 11 insurance companies called Health Promoting Entities (Entidades Promotoras de Salud, EPS).

The patient profiles were analyzed between April $1^{\text {st }}$ and September $30^{\text {th }}, 2015$, in all Colombian cities that had reliable databases. Individuals with a positive diagnosis of HIV of all ages and both genders who were treated in the different programs for the control of this disease in the EPSs were included.

The database was designed and validated by a pharmacologist who reviewed patient data one 
by one to guarantee its quality. We obtained the following groups of variables based on the information on the consumption of medications collected systematically and without interruption by the company (Audifarma, S.A.) that delivered the medications to approximately 6.5 million affiliates (corresponding to $13.8 \%$ of the country):

1. Demographic variables: age, gender, and city.

2. Antiretroviral medications prescribed and their respective doses: NRTIs (zidovudine, lamivudine, and didanosine), NNRTIs (efavirenz and nevirapine), PIs (lopinavir-ritonavir and atazanavir), fusion inhibitors (enfuvirtide), integrase inhibitors (raltegravir, elvitegravir, and dolutegravir) and coreceptor CCR5 antagonists (maraviroc). The dose used was established as a technical unit of measurement as the defined daily dose (DDD) per 1,000 inhabitants per day.

3. Regarding the type of combinations used, we identified all possible combinations of antiretroviral drugs used and we investigated whether these regimens were based on combinations established by the clinical practice guidelines for a given morbidity.

4. We determined the comorbidities and co medications patients received. To this end, medication was accepted as a substitute indicator of a disease as follows: a) Anti-ulcer drugs/ peptic acid disease; b) anti-diabetic drugs/ diabetes mellitus; c) anti-depressants/depression or neuropathic pain; d) anxiolytics and hypnotics/ anxiety or sleep disorder; e) lipidlowering drugs/ dyslipidemia; f) thyroid hormone/hypothyroidism; g) nitrovasodilators/ischemic heart disease; h) antihypertensive drugs and diuretics/arterial hypertension; i) mood stabilizers/affective bipolar disorder; j) antipsychotic drugs/schizophrenia or psychosis; k) antiepileptic drugs/epilepsy or neuropathic pain; I) antiarrhythmia drugs/ cardiac arrhythmias; m) antituberculosis drugs/ tuberculosis; n) antivirals/hepatitis B, C, herpes virus or cytomegalovirus depending on the case; o) antifungals/mycosis; p) trimethoprim/ sulfamethoxazole/pneumocystosis; q) anticoagu lants/atrial fibrillation; r) antiplatelet agents/cardio vascular prevention; s) inotropes/heart failure, and t) hormonal birth control.

The study protocol was approved by the Bioethics Committee of the Universidad Tecnológica de Pereira and respected the principles of patient confidentiality according to the Declaration of Helsinki.
The statistical program SPSS ${ }^{\mathrm{TM}} 23$ for Windows (Armonk, New York, USA) was used for data analysis. Student's t-test or analysis of variance (ANOVA) was used for the comparison of quantitative variables and the chi-square test for the categorical variables. Binary logistical regression models were applied considering the use of comedication and the need to use four or more antiretrovirals as the dependent variables. A level of statistical significance of $p<0.05$ was established.

\section{Results}

A total of 1,476 patients were undergoing anti retroviral treatment. However, fewer than three of these medications were being dispensed to 835 patients; these cases were discarded, because the medications were delivered by another provider and there was no assurance that the patients received the complete scheme, resulting in the inclusion of 641 cases in the analysis.

The 641 patients were from 28 different cities in the country and were treated by 18 health institutions. The distribution by gender showed that 386 of the patients (60.2\%) were male, and $255(39.8 \%)$ were female, with a male:female ratio of $1.5: 1.0$ and a mean age of $39.0 \pm 17$ years (range: 1-77 years). Figure 1 shows the distribution of this group of patients by age and gender.

Table 1 summarizes the prescription patterns of the ten most frequently used drugs, which are part of the list of essential medicines with which the program to control HIV/AIDS in Colombia is managed. These drugs represent $78.5 \%$ of the medications prescribed.

When considering the drugs by pharmacological group, the most prescribed agents were (in order) NRTIs (91.4\%), Pls (59.4\%), NNRTIs (44.1\%), integrase inhibitors $(23.2 \%)$, co-receptor CCR5 antagonists $(2.2 \%)$, and fusion inhibitors $(0.2 \%)$. The same table presents the DDD indicator, which shows that the majority of the drugs were being used in adequate doses in relation to those determined internationally and that ritonavir was used more as an enhancer of the Pls than as an antiretroviral.

\section{Antiretroviral combinations}

A total of 538 patients (83.9\%) were receiving three antiretrovirals, and $103(16.1 \%)$ were prescribed a combination of four or more drugs. There were 74 cases $(11.5 \%)$ receiving four, $22(3.4 \%)$ receiving 
Table 1. Patterns of prescription of the most frequently used antiretrovirals in Colombia and relation between the mean dosage and the defined daily dose (DDD)

\begin{tabular}{lccccccc}
\hline & \multicolumn{2}{c}{$\begin{array}{c}\text { Prescriptions/ } \\
\text { patients }\end{array}$} & \multicolumn{2}{c}{$\begin{array}{c}\text { Prescribed dose } \\
\text { (mg/day) }\end{array}$} & nDDD & $\begin{array}{c}\text { Sex } \\
\text { ratio }\end{array}$ & Age (mean, years) \\
\hline Drug & $\mathbf{n}$ & $\mathbf{( \% )}$ & Mean & Mode & & F:M \\
\hline Lamivudine-zidovudine & 331 & 51.6 & 261 & 300 & 0.9 & $1.4: 1$ & 35.6 \\
Lopinavir-ritonavir & 231 & 36.0 & 735 & 800 & 0.9 & $1: 2.2$ & 31.5 \\
Efavirenz & 157 & 24.5 & 807 & 600 & 0.9 & $1: 3.6$ & 38.4 \\
Raltegravir & 136 & 21.2 & 902 & 800 & 1.1 & $1: 3.6$ & 47.9 \\
Darunavir & 94 & 14.7 & 1125 & 1200 & 0.9 & $1: 3.3$ & 47.8 \\
Tenofovir-emtricitabine & 88 & 13.6 & 330 & 300 & 1.3 & $1: 3.3$ & 44.5 \\
Etravirine & 65 & 10.1 & 435 & 400 & 1.1 & $1: 5.6$ & 49.6 \\
Abacavir-lamivudine & 57 & 8.9 & 453 & 600 & 0.6 & $1: 1.5$ & 35.8 \\
Ritonavir & 37 & 5.8 & 154 & 200 & 0.1 & $1: 3.4$ & 50.9 \\
Lamivudine & 35 & 5.5 & 261 & 300 & 0.9 & $1: 1.4$ & 35.6 \\
\hline
\end{tabular}

a Relation between the mean dosage and the defined daily dose (DDD)

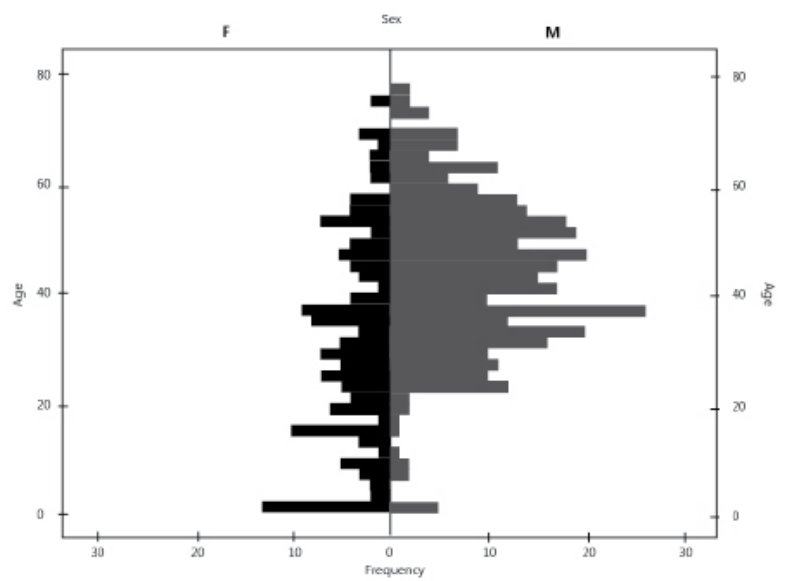

Figure 1. Distribution by age and gender of the 641 patients undergoing antiretroviral treatment in Colombia, 2015

five, $5(0.8 \%)$ receiving six, and $2(0.3 \%)$ receiving seven of these medications. The most frequently used regimens are shown in table 2, which shows the regimens used in $61.6 \%$ of the cases. The combination of lamivudine-zidovudine plus lopinavir-ritonavir represented almost one-third of the prescribed regimens. Importantly, 80 different combinations of antiretroviral drugs were found.

The multivariate analysis of the relationship between the use of four or more antiretrovirals and other variables showed that the variable age between 45 and 64 years (OR=2.25; 95\% $\mathrm{Cl}: 1.367-3.713 ; p=0.001)$ was the only variable significantly associated with a greater possibility of being treated with more medications.

\section{Comedication}

HIV infection is frequently accompanied by other pathologies that require treatment. Of the total subjects included, 267 (41.7\%) received at least one comedication ( 1 to 18 additional drugs). The most frequently found included anti-ulcer drugs ( $n=153 ; 57.3 \%)$, lipid-lowering drugs ( $n=77 ; 28.8 \%)$, anti-hypertension drugs and diuretics $(n=76$; $28,5 \%)$, antibiotics ( $n=59 ; 22.1 \%)$, antifungals $(n=56 ; 21.0 \%)$, anti-depressants $(n=39 ; 14.6 \%)$, anti-psychotics $(n=36 ; 13.5 \%)$, anxiolytics and hypnotics $(n=24 ; 9.0 \%)$ and anti-diabetics $(n=21$; $7.9 \%)$.

The multivariate analysis showed that an age older than 65 years, the use of maraviroc, and receiving treatment in the city of Bogotá were significantly associated with a higher probability of receiving at least one comedication. Conversely, the variable age between 1 and 17 years was associated with a lower risk of receiving another group of medication (table 3).

\section{Comparison among cities}

The demographic variables and some indicators of prescription were also compared among the 28 Colombian cities included in this study; however, for reasons related to the low number of patients in some of these cities, table 4 includes only the seven cities with the highest number of cases,

Table 2. Combinations of antiretrovirals most frequently used in Colombia

\begin{tabular}{lll}
\hline Antiretroviral combinations & $\mathbf{n}$ & $\%$ \\
\hline Lamivudine-zidovudine and & 189 & 29.5 \\
lopinavir-ritonavir & 105 & 16.2 \\
Lamivudine-zidovudine and efavirenz & 44 & 6.9 \\
Raltegravir, etravirine and darunavir & 29 & 4.5 \\
Raltegravir and tenofovir-emtricitabine & 29 & 4.5 \\
Efavirenz-tenofovir-emtricitabine & 245 & 38.4 \\
\hline
\end{tabular}


Table 3. Variables associated with antiretroviral treatment with comedication in binary logistic regression models, Colombia, 2015

\begin{tabular}{|c|c|c|c|c|c|c|c|c|}
\hline \multirow[t]{2}{*}{ Variables } & \multirow{2}{*}{$\mathrm{B}^{\mathrm{a}}$} & \multirow{2}{*}{$\mathrm{EE}^{\mathrm{b}}$} & \multirow{2}{*}{ Wald } & \multirow{2}{*}{$\mathrm{GL}^{\mathrm{c}}$} & \multirow{2}{*}{$\operatorname{Sig}^{d}$} & \multirow{2}{*}{$\mathrm{OR}^{\mathrm{e}}$} & \multicolumn{2}{|c|}{$95 \% \mathrm{Cl}^{\mathrm{f}}$} \\
\hline & & & & & & & Upper & Lower \\
\hline Age $1-17$ years & -1.013 & 0.414 & 5.994 & 1 & 0.014 & 0.363 & 0.162 & 0.817 \\
\hline Age $>65$ years & 1.887 & 0.532 & 12.588 & 1 & $<0.001$ & 6.599 & 2.327 & 18.715 \\
\hline Use maraviroc & 2.392 & 1.081 & 4.899 & 1 & 0.027 & 10.931 & 1.315 & 90.882 \\
\hline Be treated in Bogotá & 0.657 & 0.227 & 8.376 & 1 & 0.004 & 1.928 & 1.236 & 3.008 \\
\hline
\end{tabular}

${ }^{a}$ Regression coefficient, ${ }^{b}$ Standard error, ${ }^{c}$ Level of freedom, ${ }^{d}$ Significance level, ${ }^{e}$ Odds ratio, ${ }^{\mathrm{f}}$ Confidence interval of $95 \%$

Table 4. Comparison of some demographic variables and indicators of antiretroviral prescriptions among seven Colombian cities, 2015

\begin{tabular}{|c|c|c|c|c|c|c|c|c|}
\hline & Bogotá & Cali & Medellín & Armenia & Pereira & Barranquilla & Manizales & Colombia \\
\hline & $(n=158)$ & $(n=104)$ & $(n=74)$ & $(n=28)$ & $(n=26)$ & $(n=26)$ & $(n=21)$ & $(n=641)$ \\
\hline Mean age (years) & 33.7 & 46.3 & 39.4 & 44.6 & 44 & 37.6 & 34.7 & 38.9 \\
\hline Men (\%) & 68.4 & 68.3 & 40.5 & 35.7 & 46.1 & 80.8 & 52.3 & 60.2 \\
\hline Sex ratio $\mathrm{F}: \mathrm{M}$ & $1: 2.2$ & $1: 2.2$ & $1.5: 1$ & $1.8: 1$ & $1.4: 1$ & $1: 4.2$ & $1: 1.1$ & $1: 1.5$ \\
\hline \multicolumn{9}{|l|}{ Prescription rate (\%) } \\
\hline $\begin{array}{l}\text { Lamivudine-zidovudine and } \\
\text { lopinavir-ritonavir }\end{array}$ & 17.7 & 22.1 & 48.6 & 67.8 & 42.3 & 19.2 & 52.3 & 29.5 \\
\hline $\begin{array}{l}\text { Lamivudine-zidovudine and } \\
\text { efavirenz }\end{array}$ & 13.9 & 5.8 & 0 & 7.1 & 7.7 & 3.8 & 0 & 16.2 \\
\hline $\begin{array}{l}\text { Raltegravir,etravirine and } \\
\text { darunavir }\end{array}$ & 3.8 & 7.7 & 8.1 & 7.1 & 15.4 & 0 & 23.8 & 6.9 \\
\hline $\begin{array}{l}\text { Raltegravir and } \\
\text { tenofovir-emtricitabine }\end{array}$ & 4.4 & 10.6 & 8.1 & 3.7 & 0 & 7.7 & 0 & 4.5 \\
\hline $\begin{array}{l}\text { Efavirenz- } \\
\text { tenofovir-emtricitabine }\end{array}$ & 12 & 4.8 & 2.7 & 0 & 3.8 & 11.5 & 0 & 4.5 \\
\hline
\end{tabular}

which encompasses $68.2 \%$ of the patients. The analysis was performed as described for the total patients in the country as a whole.

\section{Discussion}

This study enabled us to determine the antiretroviral drug prescription patterns most frequently used in patients affiliated with the Health System of Colombia. The information can be used by health administrators for decision making directed towards improving the treatment of HIV/AIDS patients. It is important to highlight that the vast majority of the medications analyzed in this study are included in the list of essential medications. Therefore, they have elevated intrinsic value and are considered the pharmacological groups of choice in antiretroviral therapy. Thus, these medications are deemed sufficient for managing HIV/AIDS.

The results of this study were similar to other studies regarding the age and gender of HIV/AIDS patients. A total of $93.3 \%$ of the patients were older than 15 years, with a slightly higher prevalence of men with this pathology. This result shows that the gender gap that previously existed and that favored women with a lower frequency has been closing (3).

We found that the most prescribed antiretroviral medications were NRTIs, followed by Pls and NNRTIs. This situation is not surprising given the broad recommendation of regimens based on NRTIs (13). Nevertheless, the combination of lamivudine-zidovudine as the most formulated drug should be revised. Currently, zidovudine is not one of the drugs recommended as a first-line medication in ART due to its adverse effects (i.e., marrow suppression, lipodystrophy and lactic acidosis) and dosing type $(13,14)$. In contrast, scientific evidence supports the use of first-line regimens based on tenofovir and abacavir-lamivudine $(13,14)$. Among the PIs, the use of lopinavir-ritonavir as the second most commonly used drug (36.0\%) entails a high pill burden (the number of capsules or other dosage forms that a person takes on a regular basis), risk of metabolic changes, and low tolerability; thus, it is not the preferred PI (7). Regarding the NNRTIs, the use of efavirenz is considered adequate given 
its long-term efficacy and safety (13). The use of integrase inhibitors, coreceptor CCR5 antagonists, and fusion inhibitors is also important but has not been reported in previous studies due to their relatively recent appearance in HIV management (7).

A total of $103(16.1 \%)$ patients used four or more antiretrovirals, probably due to a failure of the initial ART. This condition is frequently associated with a lack of adherence to treatment and can be tied to the presentation of the adverse effects of these medications, the length of time the patient has had the infection, the exacerbation of comorbidities, the interactions with other drugs, the daily pill burden, and the frequency of dosing (13).

When reviewing the profiles, it was immensely surprising to find 80 different combinations of antiretroviral drugs. This finding may indicate that the diversity of prescriptions is due to a lack of adequate criteria for the implementation of regimens in accordance with scientific information and that the prescribers adopt multiple options that are beyond the recommendations made worldwide $(11,12)$.

Ritonavir has definitively positioned itself as a booster drug by inhibiting the metabolism of the different Pls and elevating their concentrations. This condition of use can be observed in this study because ritonavir is prescribed at the dose indicated for this purpose (7). In the case of the lower dose of abacavir-lamivudine, the causes should be identified because it could also be due to an improper use of the drug (15).

We found that peptic acid disease, dyslipidemias, and arterial hypertension were the most prevalent diseases, which was similar to the reports of other studies $(7,16)$.

The large number of patients with comedications for the treatment of non-communicable chronic diseases is striking; this situation reminds us of the transformation of HIV into a chronic and treatable disease and has implications for systemic repercussions in the treatment processes $(6,17)$. It is important to highlight the possible medication interactions between antiretrovirals and the drugs used for the treatment of other pathologies, especially with some anti-hypertensives of the calcium channel antagonist type wholesale reduction of blood pressure, and with lipid-lowering drugs, such as lovastatin and simvastatin by an increased risk of myopathies (18).
The finding that patients older than 65 years more frequently received other medications for the management of comorbidities is a common condition for subjects at this age, who usually suffer from other chronic non-communicable morbidities that require specific management that may have medication interactions with antiretrovirals (19-22). The association found between the use of maraviroc and the greater risk of receiving comedications may be related to treating patients who have been undergoing treatment for HIV for a longer time, are older and require an effective medication after having experienced some therapeutic failure (23).

The limitations of this study are that the data were obtained from a database and not from the patients' clinical histories and that the study subjects were affiliated only with the contributive system; therefore, the results could be extrapolated only to individuals with similar insurance characteristics. Additionally, no information on the diagnosis of the comorbidities was included. However, the study does have strengths, such as the rigor in obtaining the data and the use of a reliable population database.

The ART recommendations have constantly evolved since the very beginning. Currently, treatment is oriented towards the use of effective but less toxic drugs that have simpler dosing. In relation to this premise, the results in the present study suggest that the large number of regimens being used should be reviewed, including some that currently are not considered first-line in ART. This finding is important because a patient's adherence is improved by a lower presentation of adverse effects and greater comfort with the treatment, which is without a doubt a fundamental condition for the success of therapy.

We can conclude that the patients on ART are receiving medications with increased intrinsic value or high therapeutic utility at the recommended doses and are presenting the same comorbidities associated with chronic age-related conditions. However, they are also being treated with a great variety of regimens that are not included in the clinical practice guidelines for the management of HIV/AIDS in the country or internationally. Rational prescription habits should be fostered with the use of medications with high therapeutic value at the defined doses in combinations with sufficient scientific support.

The information found in this study may be useful for administrators of health systems and services in decision making on how their doctors are 
treating this group of patients and to improve the quality of the treatment of programs for HIV/AIDS management with the aim of reducing resistance to medications.

\section{Acknowledgments}

To Viviana Andrea Orozco, Soffy López and Andrea Orozco.

\section{Conflict of interests}

The authors declare that they have no conflict of interest.

\section{Funding}

This study was funded by the Universidad Tecnológica de Pereira and Audifarma, S. A.

\section{References}

1. Kharsany $\mathbf{A B}$, Karim QA. HIV Infection and AIDS in Sub-Saharan Africa: Current status, challenges and opportunities. Open AIDS J. 2016;10:34-48. https://doi.org/ $10.2174 / 1874613601610010034$

2. Friedland G. Marking time in the Global HIV/AIDS pandemic. JAMA. 2016;316:145-6. https://doi.org/10.1001/ jama.2016.9006

3. Fettig J, Swaminathan M, Murrill CS, Kaplan JE. Global epidemiology of HIV. Infect Dis Clin North Am. 2014;28:32337. https://doi.org/10.1016/j.idc.2014.05.001

4. Sabin CA, Lundgren JD. The natural history of HIV infection. Curr Opin HIV AIDS. 2013;8:311-7. https://doi. org/10.1097/COH.0b013e328361fa66

5. Hammer SM. Clinical practice. Management of newly diagnosed HIV infection. N Engl J Med. 2005;353:1702-10. https://doi.org/10.1056/NEJMcp051203

6. Esté JA, Cihlar T. Current status and challenges of antiretroviral research and therapy. Antiviral Res. 2010;85:2533. https://doi.org/10.1016/j.antiviral.2009.10.007

7. Pau AK, George JM. Antiretroviral therapy: Current drugs. Infect Dis Clin North Am. 2014;28:371-402. https://doi. org/10.1016/j.idc.2014.06.001

8. Sawyer JR, Ma Q, Hsiao CB. Single-tablet, once-daily treatment regimens for HIV. Lancet Infect Dis. 2014;14:2657. https://doi.org/10.1016/S1473-3099(14)70026-X

9. Volberding PA, Deeks SG. Antiretroviral therapy and management of HIV infection. Lancet. 2010;376:49-62. https://doi.org/10.1016/S0140-6736(10)60676-9

10. Maartens G, Celum C, Lewin SR. HIV infection: Epidemiology, pathogenesis, treatment, and prevention. Lancet. 2014;384:258-71. https://doi.org/10.1016/S01406736(14)60164-1

11. Machado JE, Alzate JA. Patrones de prescripción de antirretrovirales en 997 pacientes colombianos. Biomédica. 2008;28:78-86. https://doi.org/10.7705/biomedica. v28i1.110
12. Machado-Alba JE, Vidal X. Effectiveness of antiretroviral treatment in Colombia. Rev Panam Salud Pública. 2012;32:360-7.

13. Günthard HF, Aberg JA, Eron JJ, Hoy JF, Telenti A, Benson CA, et al. International Antiviral Society-USA Panel. Antiretroviral treatment of adult HIV infection: 2014 recommendations of the International Antiviral Society-USA Panel. JAMA. 2014;312:410-25. https://doi.org/10.1001/ jama.2014.8722

14. Johnson JA, Sax PE. Beginning antiretroviral therapy for patients with HIV. Infect Dis Clin North Am. 2014;28:421-38. https://doi.org/10.1016/j.idc.2014.06.003

15. Crawford KW, Ripin DH, Levin AD, Campbell JR, Flexner C, participants of Conference on Antiretroviral Drug Optimization. Optimising the manufacture, formulation, and dose of antiretroviral drugs for more cost-efficient delivery in resource-limited settings: A consensus statement. Lancet Infect Dis. 2012;12:550-60. https://doi.org/10.1016/S14733099(12)70134-2

16. Werneck-Silva AL, Prado IB. Dyspepsia in HIV-infected patients under highly active antiretroviral therapy. J Gastroenterol Hepatol. 2007;22:1712-6. https://doi.org/10. 1111/ j.1440-1746.2007.04897.x

17. Dagenais-Lussier $\mathbf{X}$, Mouna A, Routy JP, Tremblay C, Sekaly RP, El-Far M, et al. Current topics in HIV-1 pathogenesis: The emergence of deregulated immunometabolism in HIV-infected subjects. Cytokine Growth Factor Rev. 2015;26:603-13. https://doi.org/10.1016/j.cyto gfr.2015.09.001

18. Amariles P, Giraldo NA, Faus MJ. Interacciones medicamentosas en pacientes infectados con el VIH: aproximación para establecer y evaluar su relevancia clínica. Farm Hosp. 2007;31:283-302.

19. Silverberg MJ, Leyden W, Horberg MA, DeLorenze GN, Klein D, Quesenberry CP. Older age and the response to and tolerability of antiretroviral therapy. Arch Intern Med. 2007;167:684-91. https://doi.org/10.1001/archinte.167.7.684

20. Martin CP, Fain MJ, Klotz SA. The older HIV-positive adult: A critical review of the medical literature. Am J Med. 2008;121:1032-7. https://doi.org/10.1016/j.amjmed.2008.0 8.009

21. Luther VP, Wilkin AM. HIV infection in older adults. Clin Geriatr Med. 2007;23:567-83. https://doi.org/10.1016/j.cger. 2007.02.004

22. Cardoso SW, Torres TS, Santini-Oliveira M, Marins LMS, Veloso VG, Grinsztejn B. Aging with HIV: A practical review. Braz J Infect Dis. 2013;17:464-79. https://doi.org/10.1016/j. bjid.2012.11.007

23. Cottrell ML, Hadzic T, Kashuba AD. Clinical pharmacokinetic, pharmacodynamics and drug-interaction profile of the integrase inhibitor dolutegravir. Clin Pharmacokinet. 2013;52:981-94. https://doi.org/10.1007/s40262-013-0093-2 